\title{
Outcomes of operation for esophageal squamous cell carcinoma: Which approach is best?
}

\author{
Victor A. Ferraris, MD, PhD
}

See related article on pages 1006-15.

Esophageal squamous cell cancer (ESCC) is as much as $300 \%$ more prevalent in parts of China as in most Western countries (Figure 1). There are unique epidemiologic features of ESCC in this region that have been recognized for more than 2000 years. ${ }^{1}$ The article by Wang and coauthors $^{2}$ in this issue of the Journal presents a remarkable single-center experience with the surgical treatment of ESCC in a region where the disease is epidemic. Their center performs more than 300 esophageal operations for this problem per year, with noteworthy outcomes and significant long-term survival. This surgical experience is unmatched elsewhere in the world. Although surgical outcomes are good in this high-risk population, death rates for ESCC in China are among the highest in the world. Understanding this paradox requires a look at the map and an understanding of the epidemiology of the disease. Areas in China with the highest prevalence of ESCC are in the far western part of the country. The distance between Shanghai and the western part of Xinjiang Province is about 3000 miles. Across this distance, there are multiple populations at risk and wide variations in mortality. There are ethnic differences (with the Han ethnic group being at greatest risk), sex differences (ESCC is twice as common in men), and geographic differences in mortality across an area that is bigger than the United States.

Because of the high prevalence of ESCC across a wide geographic area, it is no wonder that Wang and coauthors ${ }^{2}$ have a robust surgical experience with this disease. Wang and coauthors ${ }^{2}$ present their 10 -year institutional experience with minimally invasive esophagectomy (MIE) versus open esophagectomy in the treatment of ESCC. They found improved results with MIE relative to open esophagectomy, and they recommend MIE as a safe and effective procedure for treatment of this disease in selected patients. Importantly, this experience represents only about a third of their

From the Department of Surgery, University of Kentucky, Lexington, Ky.

Disclosures: Author has nothing to disclose with regard to commercial support.

Received for publication Dec 28, 2014; accepted for publication Dec 30, 2014; available ahead of print Feb 7, 2015.

Address for reprints: Victor A. Ferraris, MD, PhD, University of Kentucky, A301 Kentucky Clinic, $740 \mathrm{~S}$ Limestone, Lexington, KY 40536-0284 (E-mail: Ferraris@earthlink.net).

J Thorac Cardiovasc Surg 2015;149:1016-7

$0022-5223 / \$ 36.00$

Copyright (c) 2015 by The American Association for Thoracic Surgery

http://dx.doi.org/10.1016/j.jtcvs.2014.12.070 operative treatment of ESCC at their institution. Their Figure 1 suggests that they use a variety of approaches for removal of the esophagus. I wonder how they selected patients for the various operations. There is inevitable selection bias in the study groups, since two-thirds of the patients had procedures other than MIE or open esophagectomy. There is selection bias even within the study group. All patients in the MIE group were not the same (some underwent laparotomy and others laparoscopy). The method for selection of the procedure for removal of the esophagus could be outlined in a more precise manner. Wang and coauthors ${ }^{2}$ suggest that patient preference was the driving force guiding the treatment options. This is a rather openended selection process and needs further definition. I think that the article would benefit from a clearer definition of their study hypothesis. Wang and coauthors ${ }^{2}$ started performing MIE in 2004. What was the reason for embarking on this method? Was their hypothesis that MIE would provide better outcomes? If so, they should compare MIE with other types of esophagectomy in a more rigorous manner. To be fair, they did try to compensate for selection bias by using propensity matching; but they ignored two-thirds of the patients who underwent esophagectomy for ESCC. Better comparison of all surgical groups would allow the reader to understand and accept the methods of Wang and coauthors $^{2}$ and their apparent preference for MIE.

I wonder about the learning curve for performing MIE. Wang and coauthors ${ }^{2}$ acknowledge that their practice evolved with time. They undoubtedly learned things along the way. Not only is there a selection bias, there is also a timeline bias in their results. It appears that the MIE procedure done in 2004 is not the same as the procedure done in 2014. The reason that this timeline is important is that readers who want to duplicate their methods and results need to understand how long it might take to achieve the apparently excellent current results presented by Wang and coauthors. ${ }^{2}$ A related issue concerns surgeon trainees. Do they train other surgeons to perform MIE? Do they have surgical residents in their hospital? What role do surgical trainees play in the care of patients undergoing MIE? Answers to these questions get at the issue of how transportable the results of Wang and coauthors ${ }^{2}$ are to other institutions, where there is not the enormous patient population at risk seen in China.

A unique feature of this article is the assessment of health-related quality of life. Wang and coauthors ${ }^{2}$ did an exceptional job of following up their patients. Most observers acknowledge the difference in esophageal cancer 


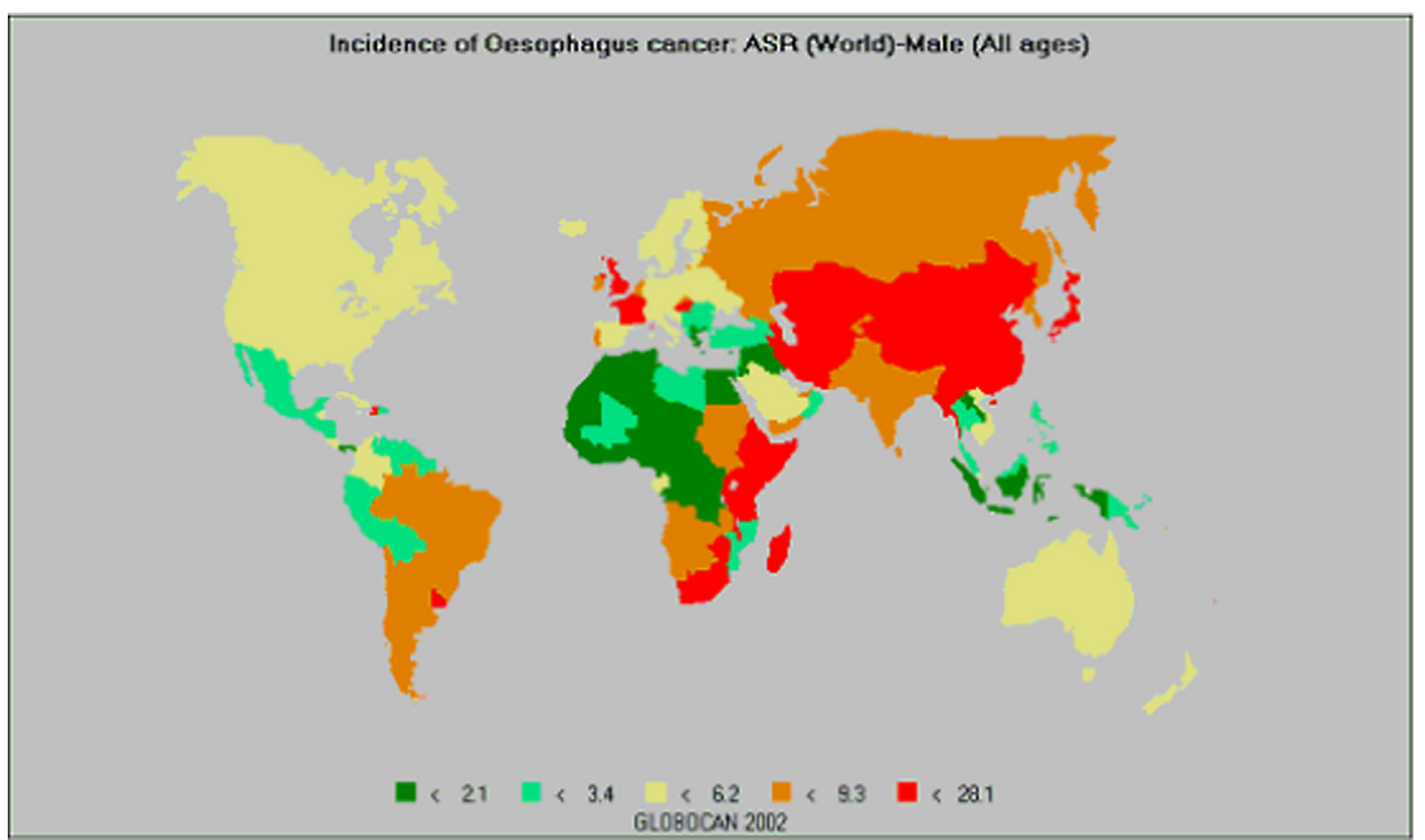

FIGURE 1. Geographic incidences of esophageal cancer in the male population.

in certain parts of China relative to other places in the world. The details of obtaining follow-up of patients in the geographically diverse population mix can only be imagined. I would love to see a map of exactly where in China the patients came from. I wonder whether patients who traveled the furthest had worse prognosis and outcomes, simply because of delays in diagnosis or treatment.

It is easy to be critical of reports like the work of Wang and coauthors. ${ }^{2}$ After all, that is what editorial comments are supposed to be, critical reviews. But there is something that needs to be said by way of the obvious. This article is a landmark article. It is doubtful that a more carefully documented single-institution study encompassing as many patients and dealing with this potentially lethal disease will appear in the literature anytime soon. Wang and coauthors ${ }^{2}$ spend a large part of their daily effort in dealing with a problem that most thoracic surgeons only see infrequently. It would behoove us all to accept and embrace the their comments and conclusions. I look forward to their continued reports of their experience. I know that there are ongoing coordinated efforts by their institution, in collaboration with others, to identify molecular mechanisms for development of ESCC and to sort out the risk factors that lead to epidemic occurrences of ESCC in China. If breakthroughs in the treatment of ESCC are in the future, I would expect these authors to be at the forefront of these advances.

\section{References}

1. Li JY. Epidemiology of esophageal cancer in China. Natl Cancer Inst Monogr 1982;62:113-20.

2. Wang H, Shen Y, Feng M, Zhang Y, Jiang W, Xu S, et al. Outcomes, quality of life, and survival following esophagectomy for squamous cell carcinoma: a propensity score-matched comparison of operative approaches. J Thorac Cardiovasc Surg. 2015;149:1006-15. 